\title{
Complete sequence of the genome of the human isolate of Andes virus CHI-7913: comparative sequence and protein structure analysis
}

\author{
NICOLE D. TISCHLER, ${ }^{1,2}$ JORGE FERNÁNDEZ, ${ }^{6}$ ILSE MÜLLER, ${ }^{5}$ RODRIGO \\ MARTÍNEZ, ${ }^{1,2}$ HÉCTOR GALENO,${ }^{6}$ ELIECER VILLAGRA,${ }^{6}$ JUDITH MORA, ${ }^{6}$ \\ EUGENIO RAMÍREZ, ${ }^{6}$ MARIO ROSEMBLATT, ${ }^{1,2,3}$ and PABLO D.T. \\ VALENZUELA ${ }^{1,2,3,4}$
}

Fundación Ciencia para la Vida ${ }^{1}$, Instituto Milenio MIFAB ${ }^{2}$, Universidad Andrés Bello ${ }^{3}$, Pontificia Universidad Católica de Chile ${ }^{4}$, Bios Chile IGSA ${ }^{5}$. Av. Marathon 1943, Santiago, Chile, Instituto de Salud Pública de Chile ${ }^{6}$. Av. Marathon 1000, Santiago, Chile

\begin{abstract}
We report here the complete genomic sequence of the Chilean human isolate of Andes virus CHI-7913. The S, $\mathrm{M}$, and $\mathrm{L}$ genome segment sequences of this isolate are 1,802, 3,641 and 6,466 bases in length, with an overall GC content of $38.7 \%$. These genome segments code for a nucleocapsid protein of 428 amino acids, a glycoprotein precursor protein of 1,138 amino acids and a RNA-dependent RNA polymerase of 2,152 amino acids. In addition, the genome also has other ORFs coding for putative proteins of 34 to 103 amino acids. The encoded proteins have greater than $98 \%$ overall similarity with the proteins of Andes virus isolates AH-1 and Chile R123. Among other sequenced Hantavirus, CHI-7913 is more closely related to Sin Nombre virus, with an overall protein similarity of $92 \%$. The characteristics of the encoded proteins of this isolate, such as hydrophobic domains, glycosylation sites, and conserved amino acid motifs shared with other Hantavirus and other members of the Bunyaviridae family, are identified and discussed.
\end{abstract}

Key terms: Hantavirus, genome sequence, RNA polymerase, human isolate

\section{INTRODUCTION}

Hantaviruses are enveloped rodent-borne negative sense RNA viruses that cause either hemorrhagic fever with renal syndrome or Hantavirus pulmonary syndrome (HPS), a severe and often fatal disease in humans (Schmaljohn and Hjelle, 1997).

Like other viruses in the Bunyaviridae family, Hantaviruses posses a tripartite RNA genome. The small or S RNA segment encodes the nucleocapsid protein $\mathrm{N}$, the medium or M RNA segment encodes a glycoprotein precursor that is cleaved into the envelope glycoproteins G1 and G2, and the large or L RNA segment, which encodes a RNA-dependent RNA polymerase.

Andes virus (ANDV) belongs to the genus Hantavirus, which was first reported in 1995 to cause several fatal cases of HPS in Argentina (López et al., 1996) and later recognized to be genetically and serologically different from others in the world and responsible for most of the HPS cases in Argentina and Chile (López et al., 1997). In Chile, 276 cases of HPS have been reported through November 2002 with a $40 \%$ mortality rate.

Up to know, knowledge of the genetic organization of ANDV has been limited to the sequence of the isolate Chile R-123 (Meissner et al., 2002) and the partial genomic sequences of isolate AH-1 (López et al., 1997; Padula et al., 2002). We report here the complete genomic sequence of the Chilean ANDV CHI7913, whose isolation from a 10-year-old HPS patient has been recently described (Galeno, et al., 2002). A preliminary account of this work has been reported (Tischler et al., 2002). 
MATERIALS AND METHODS

Virus, cells and media

The Andes virus used in this study was isolated from a 10-year-old patient who died of HPS (ANDV CHI-7913) and has been described previously (Galeno et al., 2002). Vero E6 cells were originally provided by Dr. B. Hjelle, and were grown in Eagles minimal essential medium (MEM). The virus was grown via the conventional method (Lee, H.W., 1999) in Vero E6 cells grown to confluence in T25 flasks with MEM containing $10 \%$ fetal calf serum and antibiotics. The presence of viral antigens in infected cells was confirmed by immunofluorescence as described previously (Galeno et al., 2002). All experiments involving infectious virus were performed in a bio-safety level 3 (BLS-3) laboratory.

\section{Viral RNA preparation}

Confluent mono-layers of Vero E6 cells were grown in MEM with $10 \%$ FCS and infected with ANDV isolate CHI-7913 and incubated at $37^{\circ} \mathrm{C}$ in the presence of $5 \%$ $\mathrm{CO}_{2}$. Cells were usually harvested two weeks after infection, lysed with a solution of guanidinium isothiocyanate (Cathala et al., 1983) and the contents transferred to tubes. For RNA extraction, chloroform was added to the tubes, mixed and centrifuged at $12,000 \mathrm{xg}$ for $15 \mathrm{~min}$ at $4^{\circ}$ C. The RNA present in the aqueous phase was precipitated by the addition of 0.5 volumes of isopropanol. The pellet was washed twice with $70 \%$ ethanol, air dried, and dissolved in diethyl pyrocarbonatetreated water.

Genome segment amplification and sequencing

Approximately 1-4 $\mu \mathrm{g}$ of viral RNA was used in each reverse transcriptase reaction. The oligonucleotide primers for reverse transcriptation, as well as for the initial
PCR reactions, were based on previously published well-conserved hantaviral sequences (Chizhikov et al., 1995). Subsequently ANDV CHI-7913-specific primers were designed as sequence information became available. Primers were selected as required to cover the entire genome segments by overlaps. The amplified PCR products were purified with a purification kit (Wizard PCR Preps, Promega, Madison, WI, USA), ligated to the vector pGEM-T (Promega, Madison, USA), and used to transform E. coli DH5 $\alpha$ cells. Clones with inserts of appropriate size were selected for sequencing using an ABI 310 instrument. To increase the accuracy of the sequence obtained, more than two clones from different PCR products were sequenced.

Nucleotide and amino acid sequence comparisons and analysis

The sequences of the fragments were assembled and edited into contigs using the Sequencher 4.1 and Vector NTI 6.1 programs. Nucleotide sequence analysis and comparisons were carried out using the alignment program BLASTN (NCBI). Protein alignments were realized with BLASTP (NCBI) and ClustalW, based on the Blosum62 substitution matrix. The hydrophobic domains were predicted by TmPred (EMBNet), while the Nglycosylation and O-glycosylation predictions were realized with NetNGlyc 1.0 and NetOGlyc 2.0 (CBS) respectively.

\section{RESULTS AND DISCUSSION}

Viral nucleotide sequences were determined by direct sequence analysis of RT-PCR products amplified from RNA preparations of Vero E6 cells infected with ANDV CHI7913 (Galeno et al., 2002). The nucleotide sequence has been deposited in the Gene Bank under the accession numbers AY228237, AY228238, and AY228239. The features of the nucleotide and amino acid sequence of the $\mathrm{S}, \mathrm{M}$ and $\mathrm{L}$ viral RNA segments are described below. 
$S$ segment sequence properties and comparisons

The S RNA segment of the human Andes virus isolate CHI-7913 consists of 1,802 bases encoding a nucleocapsid protein of 428 amino acids. Additionally, the sequence analysis indicates the presence of 10 ORFs; the largest of them encoding a putative protein of 81 amino acids. The ORF in the +1 frame encodes a putative protein of 63 amino acids, which could be a non-structural protein (NS) (Plyusnin, 2002), similar to the NS-S proteins of Bunyavirus, Phlebovirus and Tospovirus of the Bunyaviridae family (Elliott, 1990).

Comparisons of the nucleotide sequences of the $\mathrm{S}$ segment of the isolate ANDV CHI-7913 with ANDV Chile R123 and ANDV AH-1 reveals a sequence identity of $92 \%$ and $97 \%$ respectively, while only $83 \%$ similarity was found in comparison with the North American Sin Nombre virus (SNV), isolate NM H10. Alignment of the 504-base-long 3' noncoding region of CHI-7913 with the same region of ANDV AH-1 and ANDV Chile R123 reveals $97 \%$ and $89 \%$ identity respectively, while no significant similarity was found with the 3' non-coding region of $\mathrm{SNV}$ isolates. For Hantavirus it is known that their 3' non-coding region varies widely, both in nucleotide sequence and length (from 229 nucleotides in Prospect Hill virus to 728 nucleotides in SNV), except for the terminal nucleotides forming the panhandle structures. Assuming that the 3 ' non-coding region participates in steps of viral replication and packaging, there could be two possible explanations for the difference in their primary structures: (1) molecular mechanisms of replication differ from one host to another; or (2) the secondary rather than the primary structure of the 3' non-coding region is crucial for its proper activity (Plyusnin et al., 1996).

The 428-amino-acid nucleoprotein encoded by the $\mathrm{S}$ segment belongs to the most conserved proteins of Hantavirus and has been proven to be highly immunogenic in humans (Jenison et al., 1994, Bharadwaj et $a l ., 2000)$, thus making it the protein of choice for immunodiagnostic tests to detect virus infections. Despite its high similarity to ANDV (99\% with isolates AH-1 and Chile R123) and SNV (93\% with isolate NM H10) or other Hantavirus (e.g. 85\% with Puumala isolate Hallnas B1 and $77 \%$ with Hantaan isolate 76-118), no conserved amino acid sequence motifs could be identified in comparisons done with nucleoproteins from Bunyavirus, Phlebovirus, Nairovirus and Tospovirus. The absence of a common motif supports the theory, that determined secondary, tertiary or even quaternary structures but not sequence specific interactions are responsible for RNA binding.

\section{$M$ segment sequence properties and comparisons}

The largest ORF of the 3,641-base-long M segment RNA of isolate CHI-7913 encodes a glycoprotein precursor from nucleotide 34 to 3,450 . Another $12 \mathrm{ORFs}$ are present in the $M$ segment, encoding putative proteins between 34 and 103 amino acids. The entire M segment shows $94 \%$ identity with the ANDV isolate Chile R123, 96\% with AH-1, but only $77 \%$ with the SNV isolate NM H10. The 5' non-coding region proved to be with $100 \%$ identity highly conserved with the same region of ANDV isolates Chile R123 and AH-1, while the 3' non-coding region showed $91 \%$ and $92 \%$ identity respectively. In comparison with the 5' and 3' non-coding regions of SNV isolate NM H10, no significant similarities were found.

The 1,138-amino-acid-glycoprotein precursor encoded by the M segment RNA is the most variant protein of ANDV CHI7913 , presenting only an $87 \%$ similarity to the glycoprotein precursor of SNV isolate NM H10. When the amino acid sequence of the human isolate ANDV CHI-7913 was compared with the ANDV isolates Chile R123 and AH-1, nine non-conserved amino acid differences were found (see Table I).

Remarkable for Hantavirus glycoproteins is the high content of highly conserved cysteine residues $(5.2 \%)$ and the virtually identical hydrophobic profiles (Antic, et al., 1992), indicating a highly conserved tertiary protein structure of the hantaviral envelope proteins. 


\section{TABLE I}

Non-conserved amino acid changes among different Andes virus isolates.

Conserved amino acids were defined by the Blosum62 substitution matrix. The sign (-) indicates not available sequence information.

\begin{tabular}{|c|c|c|c|c|}
\hline Genome & Encoded residue no. & ANDV CHI-7913 & ANDV Chile R123 & ANDV AH-1 \\
\hline S segment & 148 & A & $\mathrm{T}$ & $\mathrm{T}$ \\
\hline \multirow{9}{*}{ M segment } & 23 & $\mathrm{~T}$ & $I$ & $I$ \\
\hline & 164 & $\mathrm{R}$ & $\mathrm{S}$ & $\mathrm{S}$ \\
\hline & 281 & $\mathrm{R}$ & $I$ & $\mathrm{R}$ \\
\hline & 317 & $\mathrm{~T}$ & $\mathrm{~T}$ & $I$ \\
\hline & 328 & $\mathrm{~L}$ & $\mathrm{~L}$ & $\mathrm{~F}$ \\
\hline & 705 & $S$ & $\mathrm{P}$ & $\mathrm{P}$ \\
\hline & 732 & $\mathrm{~T}$ & I & $\mathrm{I}$ \\
\hline & 938 & A & $\mathrm{T}$ & $\mathrm{T}$ \\
\hline & 1023 & A & $\mathrm{A}$ & $\mathrm{T}$ \\
\hline \multirow{12}{*}{ L segment } & 141 & I & $\mathrm{T}$ & - \\
\hline & 271 & $\mathrm{~L}$ & $\mathrm{~F}$ & - \\
\hline & 277 & $\mathrm{~S}$ & $\mathrm{~L}$ & - \\
\hline & 319 & $\mathrm{P}$ & $\mathrm{L}$ & - \\
\hline & 888 & G & $\mathrm{R}$ & - \\
\hline & 1080 & $\mathrm{~A}$ & $\mathrm{~V}$ & $\mathrm{~V}$ \\
\hline & 1138 & G & $\mathrm{E}$ & - \\
\hline & 1216 & $\mathrm{P}$ & $S$ & - \\
\hline & 1900 & $I$ & $\mathrm{~N}$ & - \\
\hline & 2108 & G & $\mathrm{D}$ & - \\
\hline & 2113 & A & $\mathrm{T}$ & - \\
\hline & 2131 & $S$ & $\mathrm{~F}$ & - \\
\hline
\end{tabular}

When Hantavirus glycoproteins are aligned with glycoproteins of Phlebovirus, Bunyavirus, Nairovirus and Tospovirus, only two of these cysteine residues (positions 768 and 773 in the CHI-7913 sequence) are maintained invariant. The cysteine residue at amino acid position 12 is only found in Hantavirus causing HPS, with the exception of Laguna Negra virus. The cysteine residues at positions 637 and 642 are associated only with South American Hantavirus (AND, Laguna Negra, Hu39694, Lechiguanas and Oran virus), while the cysteine at position 511 was found exclusively in ANDV (isolates CHI-7913, Chile R123 and AH-1). We have also found that these conserved cysteine residues are located in a highly conserved amino acid motif among members of the Bunyaviridae family (Table II). This motif (from amino acids 766 to 781) is located in the $\mathrm{N}$-terminal part of the mature G2 protein and contains in addition to the conserved cysteines, partially conserved tryptophan and glycine residues.

It has been reported that vitronectin, which binds to 33 -integrins in an arginine- glycine-aspartic acid dependent manner, inhibits the entry of SNV and New York virus (NYV) into Vero E6 cells (Gavrilovskaya et al., 1998). We have found that ANDV, SNV and NYV share six conserved amino acid sequences with human and mouse vitronectin (Table III). Of these motifs, the motif 1 (amino acids 422 to 431 ) contains a highly conserved arginine and aspartic acid, while the motif 6 (amino acids 872 to 888 ) contains two highly conserved glycines.

The predicted glycoprotein precursor of the ANDV CHI-7913 contains four hydrophobic domains. The first domain extends from the $\mathrm{N}$-terminal amino acids 1 to 19 and is most likely a hydrophobic signal peptide, which exists typically in secretory and type I trans-membrane proteins for their translocation into the lumen of the ER (Rapoport et al., 1996). A signal peptidase complex usually removes the signal sequence (Perlman and Halvorson, 1983). This seems to be also valid for Hantavirus glycoproteins, as the 


\section{TABLE II}

Conserved amino acid motif in the glycoprotein precursor of different members of the Bunyaviridae family. Bold letters indicate identical, underlined letters conserved amino acids.

\begin{tabular}{|c|c|c|c|}
\hline Virus (strain) & Genus & & Conserved Motif \\
\hline La Crosse (Human/78) & Bunyavirus & 1066 & WGCEEFGCLAESDGCV \\
\hline BUNYWV (11573) & Bunyavirus & 988 & WGCEEFGCLAVNTGCV \\
\hline SNV (NM H10) & Hantavirus & 767 & WGCNP P DCP GEGTGCT \\
\hline ANDV (CHI-7913) & Hantavirus & 766 & wGCNP GDCP GEGTGCT \\
\hline PUUV (Hallnas B1) & Hantavirus & 769 & WGCNP P DCP GVGTGCT \\
\hline HTNV (76-118) & Hantavirus & 763 & WGCNP SDCP GEGTGCT \\
\hline RVFV (ZH-548 M12) & Phlebovirus & 821 & WGCG---CFNVNP $\underline{\mathbf{S} C L}$ \\
\hline PTPV (11587) & Phlebovirus & 940 & IGCG---CFNINP $\underline{\mathbf{S}} \mathbf{C} L$ \\
\hline UUK (S23) & Phlebovirus & 646 & $\mathrm{ALC} Q---\mathbf{C} F N \underline{M} R P \underline{S} \mathbf{C F}$ \\
\hline TWSV (Brazilian BR-01) & Tospovirus & 648 & WGCEEAWCFAINEGAT \\
\hline CCHFV (Matin) & Nairovirus & 1196 & WRCNP TWCWGEGTGCT \\
\hline
\end{tabular}

TABLE III

Conserved amino acid motifs shared by glycoprotein precursors (GP) of HPS causing virus (ANDV, SNV, NYV) and the B3-integrin ligand vitronectin in comparison with nonpathogenic Hantavirus (PHV). Bold letters indicate identical amino acids, underlined letters conserved amino acids.

\begin{tabular}{|c|c|c|c|c|}
\hline Protein & & Motif 1 & Motif 2 & Motif 3 \\
\hline GP PHV (11603) & 426 & QIKFVCQRVD & 758 FLEKDYEF & 942 NSLEEWDP \\
\hline GP ANDV (CHI-7913) & 422 & $\mathrm{~K} I \mathbf{N F} I \mathrm{CQRVD}$ & 755 FFEKDYQY & 939 NKLEWIDP \\
\hline GP SNV (NM H10) & 423 & RINFMCQRVD & 756 FFEKDYQY & 940 NRLEWIDP \\
\hline GP NYV (NY-1) & 424 & $\mathrm{RINFMCQRVD}$ & 756 FFEKDYQY & 940 NRLEWIDP \\
\hline Vitronectin human (SGHU1V) & 446 & RENLRTRRVD & 272 YFFKGKQY & 420 YRMDWLVP \\
\hline Vitronectin mouse (SGMSV) & 445 & RVNLRTRRVD & 270 YFFKGKQY & 420 YDMDWLVP \\
\hline
\end{tabular}

\begin{tabular}{|c|c|c|c|}
\hline Protein & Motif 4 & Motif 5 & Motif 6 \\
\hline GP PHV (11603) & 575 MCPYCMNP & 588 SALQAHFK & $875 \underline{\text { FGDPGDIMST TPQGMQCP }}$ \\
\hline GP ANDV (CHI-7913) & 572 QCPYCMTI & 585 SALQAHYS & 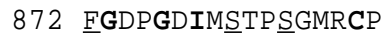 \\
\hline GP SNV (NM H10) & 573 QCPYCMTI & 586 SALQAHFA & 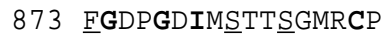 \\
\hline GP NYV (NY-1) & 573 QCPYCMTM & 586 SALQAHFA & $873 \underline{\text { FGDPGDIMSTTTGMKCP }}$ \\
\hline Vitronectin human (SGHU1V) & 458 DPPYPR $\underline{S} I$ & 299 SAVEEHFA & 200 WGIEGP IDAAFTRINCQ \\
\hline Vitronectin mouse (SGMSV) & 457 NPPYPR $\underline{S} I$ & 297 SAVEEHFA & 199 WGIEGPIDAAFTRINCQ \\
\hline
\end{tabular}


exact N-terminus of the mature G1 protein of Hantaan virus as been determined to start at the position threonine 18 (Schmaljohn et al., 1987). Studies of B cell epitopes confirm this results also for ANDV, as sera of patients infected with ANDV revealed a strong reactivity with a peptide carrying amino acids 14-26, but not with a peptide carrying amino acids 1-13 (N. Tischler, unpublished data). The second and fourth hydrophobic domains (aa 490 to aa 509 and aa 1,109 to aa 1,129 ) are potential transmembrane regions for each mature glycoprotein. The third hydrophobic region extends from amino acids 630 to 648 and is probably a second signal peptide for the cleavage of the glycoprotein precursor into the mature $\mathrm{G} 1$ and $\mathrm{G} 2$ proteins. The cleavage probably occurs at the highly conserved pentapeptide WAASA (Loeber et $a l ., 2001)$, also present in the ANDV CHI7913 sequence.

Oligosaccharide chains are essential components for the correct folding of the glycoproteins and participate in many molecular recognition reactions of receptors and ligands. They can also determine whether viral envelope proteins are recognized by components of the host immune defense system. Hence, glycosylation differences could be related to pathogenic differences of virus strains.

Previous studies showed that only ANDV produce HPS synthomes in Syrian Hamsters while SNV does not (Hooper et al., 2001). To investigate if those differences in pathogenesis could be realted with a different glycosylation pattern, the glycosylation prediction of amino acid sequences of 8 North American Hantavirus and 7 South American Hantavirus were compared. Five putative asparagine glycosylation sites with the characteristic sequence NXS/T (where $\mathrm{X}$ is any amino acid different to proline) are predicted for the ANDV CHI-7913 glycoprotein precursor. Of these, only four are conserved in HPS-associated Hantavirus (aa 138-141, aa 350-353, aa 402-405, aa 930-933). The fifth putative $\mathrm{N}$-glycosylation site, which comprises the aa 524527 , was found in all of the South American Hantavirus studied, except in Laguna Negra virus. Within the
North American Hantavirus this site is present only in the Limestone Canyon and Prospect Hill virus (Table IV), of which no human infection has been determined (Schmaljohn et al., 1997). Based on mucintype O-glycosylation prediction, three main O-glycosylation clusters could be defined (Table IV). Among HPS associated Hantavirus, threonine 93 was found to be the only conserved putative O-glycosylation site, while threonine 92, threonine 583 and serine 307 are conserved in all of the South American Hantavirus. Interestingly, the glycosylation of serine 97 was predicted only for all South American Hantavirus, excluding Oran and Lechiguanas virus, which instead have an alanine residue. Additionally, the putative glycosylation cluster of serine 307, threonine 308 and serine 309 present in site 2 is found in all South American Hantavirus, with the exception of Laguna Negra virus, which presents an amino acid change of threonine 308 into serine. In contrast, the glycosylation of threonine 89 present in site 1 is predicted only for all North American Hantavirus, while threonine 90 is found to be glycosylated in all North American Hantavirus except Limestone Canyon and Bayou virus.

\section{L segment sequence properties and comparisons}

The 6,466-base-long L segment RNA of CHI7913 contains a 6,453 base long ORF (nucleotide 9-6,464), which encodes a protein of 2,152 amino acids possessing at least the activity of a RNA dependent RNA polymerase. Additionally, another 21 ORFs, which encode putative proteins of 34 to 100 amino acids, are present. Nucleotide sequence comparison analysis with the $\mathrm{L}$ segment of another complete genome of ANDV (Chile R123) revealed $93 \%$ of identity, while the identity with the L segment of SNV virus isolate NM H10 amounted to $72 \%$. Notably, in six regions of the SNV L segment no significant similarity was found (see Table V). However, when translating those regions into the corresponding amino acid sequence, similarities between $76 \%$ and $96 \%$ could be determined. This result emphasizes the 


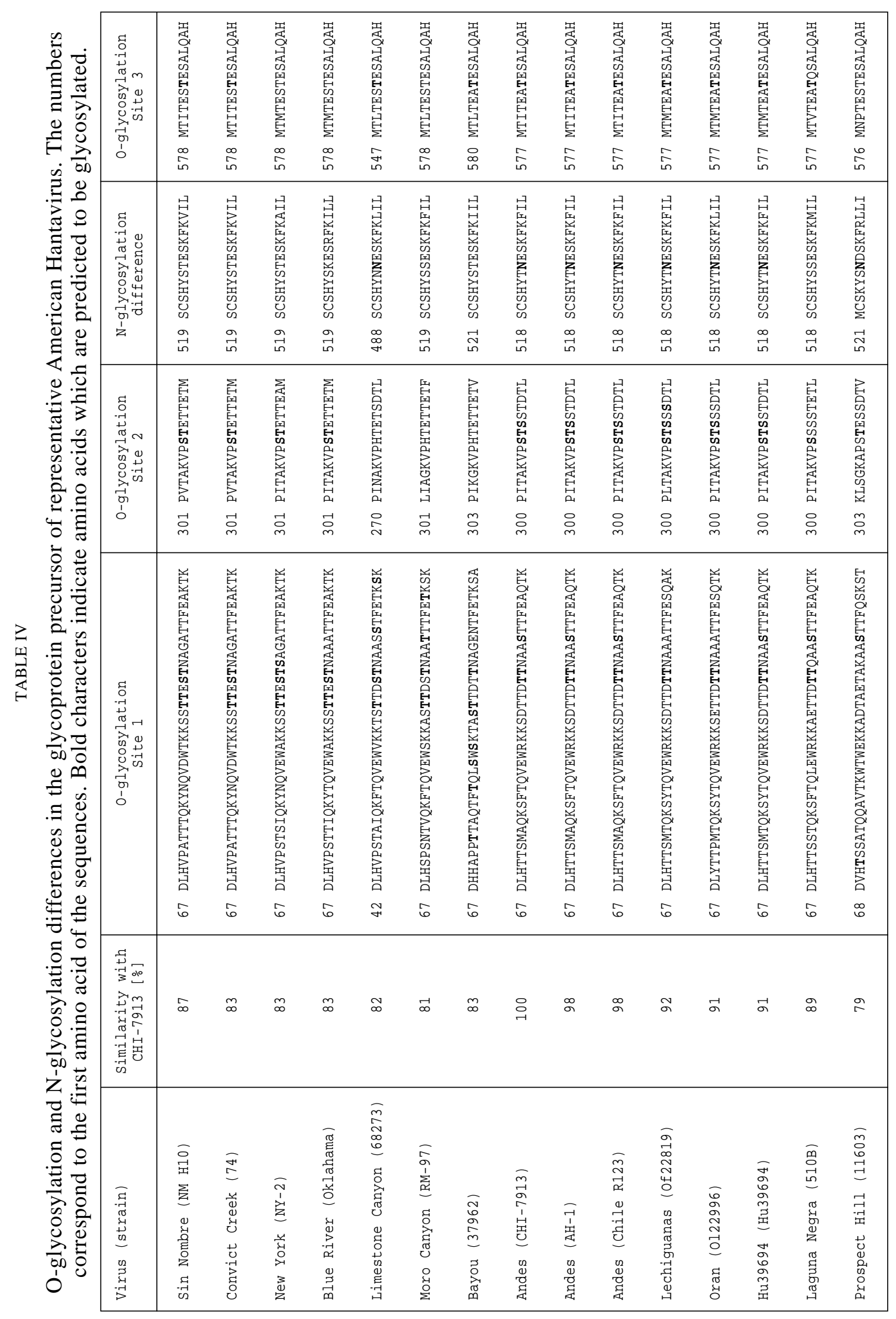




\section{TABLE V}

Different codon usage of AND and SN virus L segments. Alignments between L segments and encoded proteins of ANDV isolates CHI-7913, Chile R123 and SN virus NM H10. The sign (-) indicates no significant similarity (E value $>10)$.

\begin{tabular}{lcccc}
\hline & \multicolumn{3}{c}{ Sequence comparisons } \\
\cline { 2 - 5 } Nucleotide & ANDV Chile & SNV NM H10 & \\
sequence of the L & R123 & & Encoded amino acids & \\
segment of ANDV & Nucleotide & Nucleotide & Identity (\%) & Similarity (\%) \\
CHI-7913 & identity (\%) & identity (\%) & 69 & 76 \\
\hline $417-497$ & 91 & - & 70 & 85 \\
$595-917$ & 91 & - & 62 & 84 \\
$1186-1336$ & 98 & - & 87 & 96 \\
$3878-3962$ & 95 & - & 66 & 84 \\
$4574-4862$ & 94 & - & & \\
$6314-6465$ & 94 & & & 89 \\
\hline
\end{tabular}

difference of codon usage in these regions by the ANDV and SNV. However, the conservation of the predicted primary structure of the protein, despite extreme mutations in the nucleotide sequence, could be a result of evolutionally adaptation of the virus to the host codon usage.

The protein of 2,152 amino acids encoded by the L segment of CHI-7913 shows an overall identity of $98 \%$ with ANDV R123, while the similarity with SNV NM H10 amounts to $94 \%$. When the derived amino acid sequence of the human isolate CHI-7913 was compared with isolates Chile R123 (complete sequence) and AH-1 (sequence from aa 933 to 1134), twelve non-conserved amino acid changes were found (see Table I).

The deduced amino acid sequence of ANDV CHI-7913 RNA polymerase contains the six motifs previously identified as common to all RNA-dependent RNA polymerases (Poch et al., 1989; Müller et al., 1994), which have been suggested to be related to polymerase function (Müller et al., 1994). All of these motifs are located in the most highly conserved middle region of the protein (from amino acids 860 to 1180 ). A sequence alignment with other members of the Bunyaviridae family is shown in Table VI. Motif preA characterized by the presence of three strictly conserved basic residues is present between lysine 885 and glutamic acid 910 of ANDV CHI-7913. The first two conserved basic residues of this motif, lysine 885 and arginine 893, are probably part of the "finger sub-domain" of a proposed "right hand" structural model of polymerases (Ollis et al., 1985; Kohlstaedt et al., 1992) and discussed in more detail by Hansen et al., (1997) and O'Really and Kao, (1998). These two residues may participate in positioning and binding. It has been suggested that the third positively charged residue, arginine 903 in ANDV CHI-7913 is located in the vicinity of the active site, close to the binding site of the template strand (Müller et al., 1994).

Motif A, located between residues lysine 964 and aspargine 982 in ANDV CHI-7913 and motif $\mathrm{C}$, located between phenylalanine 1103 and aspargine 1116 in ANDV CHI7913 (Table VI), are characterized by the presence of strictly conserved aspartic acid residues which have been suggested to be part of the active site (Delarue et al., 1990) and to participate in the binding of metal ions involved in catalysis by the Klenow fragment (Beeze and Steitz, 1991). Motif B, located between residues alanine 1053 and alanine 1074 of ANDV CHI-7913 (Table $\mathrm{VI}$ ), is characterized by the presence of a strictly conserved glycine residue and may also participate in template binding (Müller et al., 1994). Motifs D and E, located between glycine 1154 and phenylalanine 
TABLE VI

Conserved amino acid motifs among polymerases of different genus members of the Bunyaviridae family. Bold letters indicate identical, underlined letters conserved amino acids.

\begin{tabular}{|c|c|c|c|}
\hline Virus (strain) & Genus & Pre-Motif A & Motif A \\
\hline La Crosse (Human/78) & Bunyavirus & 950 KGQKTSKDREIFVGEYEAKMCMYAVE & 1051 KGLKMEINADMSKWSAQDV \\
\hline BUNYWV (11573) & Bunyavirus & 881 KGQKTAKDREIFVGEEEAKMCMYVVE & 958 KALKLEINADMSKWSAQDV \\
\hline SNV (NM H10) & Hantavirus & 885 KYQRTEADRGFFITTLPTRVRLEIIE & 964 KRRLMYVSADATKWSPGDN \\
\hline ANDV (CHI-7913) & Hantavirus & 885 KYQGTEADRGFFITTLPTRVRLEIIE & 964 KRKLMYVSADATKWSPGDN \\
\hline PUUV (Hallnas B1) & Hantavirus & 814 KYQRTEADRGFFITTLPTRVRLEIIE & 893 KRKLMYVSADATKWSPGDN \\
\hline HTNV (76-118) & Hantavirus & 814 KYQRTEADRGFFITTLPTRCRLEIIE & 893 KRKLMYVSADATKWSPGDN \\
\hline RVFV (ZH-548 M12) & Phlebovirus & $848 \mathrm{KKQQHGGLREIYVMGAEERIVQSVVE}$ & 910 PVWTCATSDDARKWNQGHF \\
\hline TOSV (ISS.PHL.3) & Phlebovirus & 849 KKQQHGGLREIYVMGADERIVQSVIE & 913 SVWTCATSDDARKWNQGHY \\
\hline UUKV (S23) & Phlebovirus & 852 KPQ-HGGLREIYVLGFEERVVQLVIE & 916 HHETVATSDDAAKWNQCHH \\
\hline TWSV (Brazilian BR-01) & Tospovirus & 1282 KMQRTKTDREIYLMSMKVKMMLYFIE & 1350 KSRLAFLSADQSKWSASGL \\
\hline
\end{tabular}

\begin{tabular}{|c|c|c|c|c|c|c|}
\hline Virus (strain) & & Motif $B$ & & Motif C & & Motif $D$ and $E$ \\
\hline La Crosse (Human/78) & 1139 & VLIKRNWLQGNFNYTSSYVHCS & 1178 & ILVNSLVHSDDNQT & 1220 & FGCQANMKKTYVTNCIKEFVSLF \\
\hline BUNYWV (11573) & 1046 & VQIKRNWLQGNFNYISSYVHSC & 1085 & CLINSMVHSDDNQT & 1127 & FGCQANMKKIYYITHTCKEFVSLF \\
\hline SNV (NM H10) & 1053 & ATVKGNWLQGNLNKCSSLFGAA & 1103 & FIYGYLEPEDDGTD & 1154 & GSIKVSPKKITVS $P$ TNAEFLSTF \\
\hline ANDV (CHI-7913) & 1053 & ANVKGNWLQGNLNKCSSLFGAA & 1103 & FIYGYLEPEDDGTD & 1154 & GSIKVSPKKITVI SPTNAEFLSTF \\
\hline PUUV (Hallnas B1) & 982 & ASIKGNWLQGNLNKCSSLFGAA & 1032 & FIYGYLEPVDDGTE & 1083 & GSIKISPKKITVISP TNAEFLSTF \\
\hline HTNV (76-118) & 982 & GEVKGNWLQGNLNKCSSLFGVA & 1032 & FIYGYLEPVDDGTD & 1083 & GSIKISPKKTIVSSPTNAEFLSTF \\
\hline RVFV (ZH-548 M12) & 1008 & LETTTGMMQGILHYTSSLLHTI & 1054 & LVCDMMQGSDDSSM & 1100 & LAIYPSEKSTANTDEVMEYNSEF \\
\hline TOSV (ISS.PHL.3) & 1009 & LKTSTGMMQGILHFTSSLLHSL & 1055 & VVCDMMQGSDDSSM & 1101 & IGIYPSEKSIPNIDDFVMEYNSEF \\
\hline UUKV (S23) & 1013 & VQTETGMMQGILHYTSSLLHTL & 1059 & VLVDVLQSSDDSGM & 1105 & LGIYSSVKSTNNTLHLLEFNSEF \\
\hline TWSV (Brazilian BR-01) & 1444 & YPVSMNWLQGNLNYLSSVYHSC & 1482 & FQTRWIVHSDDNAT & 1530 & FCITLNPKKSYASSSSEVEF ISER \\
\hline
\end{tabular}

1176 in ANDV CHI-7913 (Table VI), are characterized by the presence of strictly conserved glycine, glutamic acid and serine residues. Motifs preA, A, B, C, D and E have been associated to the "right hand" structural model of RNA polymerases of which motifs A, B, C and D are present in all polymerases, while motif preA is only found in RNA dependent RNA polymerases and motif E only in polymerases of segmented, negative-stranded RNA virus (Hansen et al., 1997; O’Really and Kao, 1998).

The complete sequence of the genome and the comparative analysis of the predicted translated proteins of the human isolate ANDV CHI-7913 reported here represents additional information to those reported in the past (López et al., 1997, Padula et al. 2002, Meissner et al, 2002). This will allow further sequence comparisons useful in future studies of ANDV pathogenicity and the development of immunodiagnostics, vaccines and potential immunotherapeutic agents.

\section{ACKNOWLEDGMENTS}

We are grateful to Dr. Luis Burzio for helpful discussions during the course of this research and for critical reading of this manuscript. We also want to express our 
special thanks to Danilo González of the University of Santiago de Chile for his valuable support in bioinformatics.

\section{REFERENCES}

ANTIC D, WRIGHT KE, KANG CY (1992) Maturation of Hantavirus proteins G1 and G2. Virol 189: 324-328

BEEZE L, STEITZ TA (1991) Structural basis for the 3'-5' exonuclease activity of $E$. coli DNA polymerase I: a two metal ion mechanism. EMBO J 10:25-33

BHARADWAJ M., NOFCHISSEY R., GOADE D, KOSTER F, HJELLE B (2000) Humoral immune responses in the Hantavirus cardiopulmonary syndrome. J Inf. Dis 182:43-48

CATHALA G, SAVOURET F, MÉNDEZ B, WEST B, KARIN M, MARTIAL J, BAXTER J (1983) A method for isolation of intact, translationally active ribonucleic acid. DNA 2(4):329-35

CHIZHIKOV VE, SPIROPOULOU CF, MORZUNOV SP, MONROE MC, PETERS CJ, NICHOL ST (1995) Complete genetic characterization and analysis of isolation of Sin Nombre Virus. J Virol 69:8132-8136

DELARUE M, POCH O, TORDO N, MORAS D, ARGOS $P$ (1990) An attempt to unify the structure of polymerases. Protein Eng 3: 461-467

ELLIOTT RM (1990) Molecular biology of the Bunyaviridae. J Gen Virol 71: 501-522

GAVRILOVSKAYA IN, SHEPLEY M, SHAW R, GINSBERG M, MACKOW E (1998) B3 integrins mediate the cellular entry of Hantaviruses that cause respiratory failure. Proc Natl Acad Sci USA 95: 70747079

GALENO H., MORA J, VILLAGRA E, FERNÁNDEZ J, HERNÁNDEZ J, MERTZ GJ, RAMÍREZ E (2002) First human isolate of Hantavirus (Andes virus) in the Americas. Emerg Infect Dis 8: 657-661

HANSEN JL, LONG AM, SCHULTZ SC (1997) Structure of the RNA dependent RNA polymerase of poliovirus. Current Biol Struct 5: 1109-1122

HOOPER JW, LARSEN T, CUSTER DM, SCHMALJOHN CS (2001) A lethal disease model for hantavirus pulmonary syndrome, Virology 10; 289(1): 6-14

JENISON S, YAMADA T, MORRIS C, ANDERSON B, TORREZ-MARTÍNEZ N, KELLER N, HJELLE B (1994) Characterization of human antibody responses to Four Corners Hantavirus infections among patients with Hantavirus pulmonary syndrome. J Virol 68: 3000-3006

KOHLSTAEDT LA, WANG J, FRIEDMAN JM, RICE PA, STEITZ TA (1992) Crystal structure at $35 \mathrm{~A}^{\circ}$ resolution of HIV-1 reverse transcriptase complexed with an inhibitor. Sci $256: 1783-1790$

LEE HW (1999) Virus isolation. In: LEE HW, CALISHER C, SCHMALJOHN C (Eds). Manual of hemorrhagic fever with renal syndrome and Hantavirus pulmonary syndrome. Seoul: WHO Collaborating Centre for Virus Reference and Research (Hantavirus). pp:74-79

LOEBER C, ANHEILER B, LINDOW S, KLENK HD, FELDMANN H (2001) The Hantaan virus glycoprotein precursor is cleaved at the conserved pentapeptide WAASA: Virol 289: 224-229

LÓPEZ N, PADULA P, ROSSI C, LÁZARO ME, FRANZE-FERNÁNDEZ MT (1996) Genetic identification of a new Hantavirus causing severe pulmonary syndrome in Argentina. Virol 220: 223-226

LÓPEZ N, PADULA P, ROSSI C, MIGUEL S, EDELSTEIN A, RAMÍREZ E, FRANZEFERNÁNDEZ MT (1997) Genetic characterization and phylogeny of Andes virus and variants from Argentina and Chile. Virus Res 50: 77-84

MEISSNER JD, ROWE JE, BORUCKI MK, STEPHEN CSJ (2002) Complete nucleotide sequence of a Chilean Hantavirus. Virus Res 89: 131-143

MÜLLER R, POCH O, DELARUE M, BISHOP DHL, BOULOY M (1994) Rift Valley fever virus L segment: correction of the sequence and possible role of newly identified regions conserved in RNA-dependent polymerases. J Gen Virol 75: 1345-1352

OLLIS DL, BRICK P, HAMLIN R, XUONG NG, STEITZ TA (1985) Structure of the large fragment of E. coli DNA polymerase I complexed with dTMP. Nature 343:762-766

OREILLY E.K, KAO CC (1998) Analysis of RNAdependent RNA polymerase structure and function as guided by known polymerase structures and computer predictions of secondary structure. Virol 252: 287-303

PADULA PJ, SÁNCHEZ AJ, EDELSTEIN A, NICHOL ST (2002) Complete nucleotide sequence of the M RNA of Andes virus and analysis of the variability of the termini of the virus S, M and L RNA segments. J Gen Virol 83: 2117-2122

PERLMAN D, HALVORSON HO (1983) A putative signal peptidase recognition site and sequence in eucaryotic and procaryotic signal peptides. J Mol Biol 167: 391-409

PLYUSNIN A, VAPALAHTI O, VAHERI A (1996) Hantavirus: genome structure, expression and evolution. J Gen Virol 77: 2677-2687

PLYUSNIN, A (2002) Genetics of hantaviruses: implications to taxonomy, Arch. Virol. 147: 665-682

POCH O, SAUVAGET I, DELARUE M, TORDO N (1989) Identification of four conserved motifs among the RNAdependent polymerase elements EMBO J 8: 3867-3874

RAPOPORT TA, JUNGNICKEL B, KUTAY U (1996) Protein transport across the eucaryotic endoplasmatic reticulum and bacterial inner membranes. Ann Rev Biochem 65: 271-303

SCHMALJOHN C, HJELLE B (1997) Hantaviruses: A global disease problem. Emerg Infect Dis 3: 95-104

SCHMALJOHN CS, SCHMALJOHN AL, DALRYMPLE JM (1987) Hantaan virus M RNA: Coding strategy, nucleotide sequence, and gene order. Virol 157, 31-39

TISCHLER N, LISBONA F, MÜLLER I, MARTÍNEZ R, FERNÁNDEZ J, ROSEMBLATT M, VALENZUELA $P$ (2002) Secuencia y expresión de genes de virus Hanta Andes. Biol Res 35: R-104 